\title{
Erratum to: A pattern-based method for establishing a cloud-specific information security management system
}

\author{
Kristian Beckers • Isabelle Côté • Stephan Faßbender • \\ Maritta Heisel · Stefan Hofbauer
}

Published online: 4 July 2013

(C) Springer-Verlag London 2013

\section{Erratum to: Requirements Eng \\ DOI 10.1007/s00766-013-0174-7}

Figure 23 published in the original version is not correct. The correct figure is given below:

The online version of the original article can be found under doi:10.1007/s00766-013-0174-7.

\section{K. Beckers $(\bowtie) \cdot$ S. Faßbender $\cdot$ M. Heisel}

Paluno, The Ruhr Institute for Software Technology, University of Duisburg-Essen, Oststrasse 99, 47057 Duisburg, Germany e-mail: kristian.beckers@paluno.uni-due.de

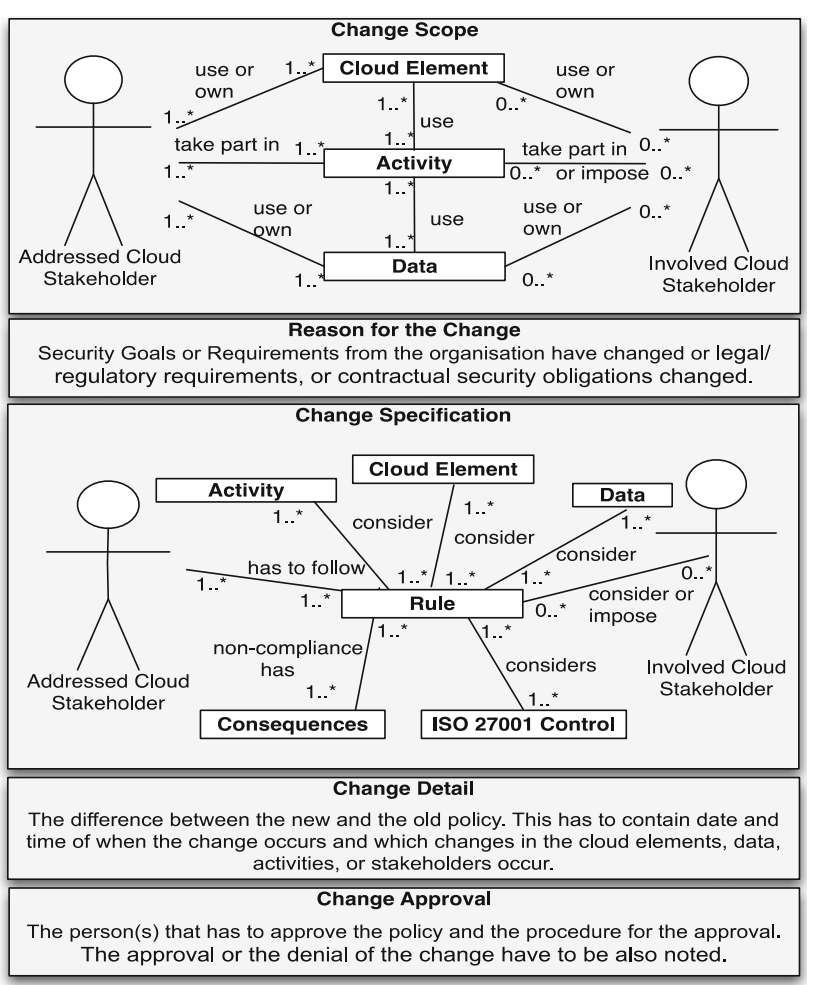

Fig. 23 Policy change pattern

S. Faßbender

e-mail: stephan.fassbender@paluno.uni-due.de

M. Heisel

e-mail: maritta.heisel@paluno.uni-due.de

I. Côté

ITESYS Institute for Technical Systems GmbH,

Emil-Figge-Str. 76, 44227 Dortmund, Germany

e-mail: Isabelle.Cote@itesys.de

\section{S. Hofbauer}

Network Integration Services Department,

Amadeus Data Processing GmbH,

Berghamer Straße 6, 85435 Erding, Germany

e-mail: stefan.hofbauer@amadeus.com 